\title{
PEMANFAATAN SERBUK KACA DARI JENIS KACA BENING DENGAN KETEBALAN 3-4 MM SEBAGAI BAHAN TAMBAH DALAM PEMBUATAN BATAKO
}

\author{
Ali Syafi'urroziq *1, Yosef Cahyo SP ${ }^{2}$, Lucia Desti Krisnawati ${ }^{3}$. \\ ${ }^{1,2,3}$ Fakultas Teknik, Universitas Kadiri. \\ e-mail:*1elalifidausi4@gmail.com, 2yosef.cs@unik-kediri.ac.id, \\ 3 lucia_desti@unik-kediri.ac.id.
}

\begin{abstract}
Batako is a building material to replace brick, which is composed of sand, portland cement, and water. This type of research is an experimental study in the form of compressive strength testing with the addition of glass powder. We are planning a mixture of brick making materials with a ratio of 1: 6 cement and sand. Making the test object size and external appearance and testing the absorption capacity using a mortar specimen measuring $5 \times 5 \times 5 \mathrm{~cm}$. Variations in adding glass powder by reducing the amount of sand starting from $0 \%, 10 \%, 15 \%, 20 \%$, and $25 \%$ of the weight of the sand. Testing of the mechanical properties of the brick was carried out at the age of 7, 14, and 28 days for the compressive strength test of the brick, and 28 days for the absorption test of the brick. The compressive strength of the concrete blocks increases with age. From the test, it was concluded that the most optimum mixture was the concrete block with a mixture concentration of 25\%, namely $58.00 \mathrm{~kg} / \mathrm{cm}^{2}$ for the results of the concrete block compressive strength test and 11.19 grams for the brick absorption test.
\end{abstract}

Keywords: $\quad$ Brick, Compressive Strength, Water Absorption, Glass Powder

\begin{abstract}
Abstrak
Batako merupakan bahan bangunan pengganti batu bata yang tersusun dari pasir, semen portland dan air. Jenis penelitian ini adalah penelitian eksperimen berupa pengujian kuat tekan dengan penambahan serbuk kaca. Perencanaan campuran bahan penyusun batako dengan perbandingan 1:6 semen dan pasir. Pembuatan benda uji ukuran dan tampak luar dan pengujian daya serap menggunakan benda uji mortar ukuran $5 \times 5 \times 5 \mathrm{~cm}$. Variasi penambahan serbuk kaca dengan mengurangi jumlah pasir mulai dari $0 \%$, $10 \%, 15 \%, 20 \%$, dan $25 \%$ dari berat pasir. Pengujian sifat mekanik batako dilakukan pada umur 7, 14, dan 28 hari untuk uji kuat tekan batako, dan 28 hari untuk uji penyerapan batako. Kuat tekan batako meningkat seiring dengan bertambahnya umur. Dari pengujian disimpulkan bahwa campuran yang paling optimum adalah batako dengan konsentrasi campuran $25 \%$ yaitu $58.00 \mathrm{~kg} / \mathrm{cm}^{2}$ untuk hasil uji kuat tekan batako dan 11.19 gram untuk uji serapan batako.
\end{abstract}

Kata Kunci : $\quad$ Batako, Kuat Tekan, Daya Serap Air, Serbuk Kaca 


\section{PENDAHULUAN}

Batako merupakan bahan bangunan berupa bata cetak alternatif pengganti batu bata yang tersusun dari komposisi antara pasir, semen portland dan air, . Batako difokuskan sebagai konstruksi-konstruksi dinding bangunan non struktural [1]. Batako merupakan salah satu alternatif bahan dinding yang murah dan relatif kuat.Meskipun sifatnya hanya bagian non struktural dari bangunan bukan berarti batako tidak memiliki standar kekuatan dan toleransi yang harus dipenuhi, karena dalam penggunaannya batako dengan mutu tertentu dapat dipakai dalam konstruksi yang memikul beban, [2]. Terdapat batasan-batasan tertentu sebagai persyaratan pada batako agar dalam penggunaannya, batako memiliki ketahanan dari berbagai macam pengaruh baik pengaruh secara langsung ataupun tidak langsung seperti ketentuan di dalam Standar Nasional Indonesia, [3].

\subsection{Latar Belakang}

Semakin banyaknya permintaan batako di pasaran akan meningkatkan kebutuhan bahan baku utama konstruksi, salah satunya adalah pasir. Dengan meningkatnya kebutuhan akan pasir, maka harga pasir pun akan semakin tinggi. Ini tentu menjadi satu masalah, terutama di daerah-daerah yang minim terdapat sumber bahan baku kontruksi salah satunya adalah pasir. Sehingga tidak heran harga pasir di daerah tersebut sangat mahal. Hal ini terus memicu para ahli teknik untuk mengembangkan suatu bahan yang dapat menggantikan atau mengurangi kebutuhan dari salah satu bahan konstruksi tersebut untuk mengurangi biaya bahan baku tanpa mengurangi kualitas hasil. Salah satu bahan alternatif yang dapat digunakan untuk mengganti pasir adalah serbuk kaca sebagai bahan tambah pada batako.

\subsection{Rumusan Masalah}

Berdasarkan uraian diatas timbul permasalahan yang menarik untuk diteliti yaitu :

1. Bagaimana pengaruh kuat tekan batako dengan penambahan campuran serbuk kaca dengan konsentrasi $0 \%, 10 \%, 15 \%, 20 \%, 25 \%$ ?

2. Bagaimana pengaruh daya resap air batako dengan penambahan campuran serbuk kaca dengan konsentrasi $0 \%, 10 \%, 15 \%, 20 \%, 25 \%$ ?

\subsection{Batasan Masalah}

Data yang diharapkan dari penelitian ini yaitu tentang uji kuat tekan dan daya serap air pada batako dengan penambahan campuran serbukkaca.Macam dan jenis penelitian akan dibatasi permasalahan sebagai berikut :

A. Konsentrasi variasi komposisi campuran bahan susun batako :

1. \%serbuk kaca : 1 semen : 6 pasir

2. $10 \%$ serbuk kaca : 1 semen : 6 pasir

3. $15 \%$ serbuk kaca : 1 semen : 6 pasir 
4. $20 \%$ serbuk kaca : 1 semen : 6 pasir

5. $25 \%$ serbuk kaca : 1 semen : 6 pasir

B. Benda uji berukuran $5 \times 5 \times 5 \mathrm{~cm}$

C. Pengujian kuat tekan berumur 7, 14, dan 28 hari.

D. Serbuk kaca yang dipakai adalah serbuk kaca dari jenis kaca bening (float glass) dengan ketebalan 3-4 mm yang di dapat dari pengrajin etalase di desa Plosokandang Kedungwaru Tulungagung.

E. Pemeriksaan terhadap agregat halus meliputi pemeriksaan agregat, berat jenis agregat halus, bobot isi agregat halus, kadar air agregat halus, kandungan lumpur agregat halus.

F. Pasir yang dipakai adalah pasir sungai Brantas Ngujang Tulungagung.

G. Semen yang dipakai adalah semen holcim.

\subsection{Maksud dan Tujuan Penelitian}

Dari hasil penelitian ini diharapkan dapat memberikan kontribusi yang bermanfaat bagi perkembangan ilmu pengetahuan dan masyarakat diantaranya :

1. Mengetahui kuat tekan batako dengan penambahan campuran serbuk kaca dengan konsentrasi $0 \%, 10 \%, 15 \%, 20 \%, 25 \%$.

2. Mengetahui daya resap air batako dengan penambahan campuran serbuk kaca dengan konsentrasi $0 \%, 10 \%, 15 \%, 20 \%, 25 \%$.

3. Dapat mengurangi pencemaran lingkungan.

4. Dapat merubah barang yang tidak mempunyai nilai ekonomi menjadi barang yang mempunyai nilai ekonomi dan bermanfaat.

\section{METODE PENELITIAN}

\subsection{Tinjauan Pustaka}

Batako merupakan salah satu bahan bangunan penyusun untuk dinding pada bangunan/gedung[4]. Seperti paving block, batako berasal dari kata bata concrete atau bata beton dalam bahasa teknik sering disebut bataton. Bata ini tidak dibuat dari tanah liat seperti umumnya bata merah, tetapi campuran bahan pembuatan batako atau bataton ini layaknya beton, yaitu pasir, semen, kericak dan air. Beberapa produsen batako ada juga yang memproduksi tanpa menggunakan kericak, tapi hasilnya kurang bagus jika dibandingkan dengan batako yang bahan penyusunnya seperti membuat beton, [5][6][7].

Batako yang baik adalah yang masing- masing permukaannya rata dan saling tegak lurus serta mempunyai kuat tekan yang tinggi, [8]. Persyaratan batako menurut Persyaratan Umum Bahan Bangunan di Indonesia 1982 pasal 6 antara lain adalah berumur minimal satu bulan, 
pada waktu pemasangan harus sudah kering, berukuran panjang $\pm 400 \mathrm{~mm}$, lebar $\pm 200 \mathrm{~mm}$, tebal $\pm 100-200 \mathrm{~mm}$, kadar air $25-35 \%$ dari berat, dan memiliki kuat tekan antara 2-7 N/mm2. Berdasarkan persyaratan fisik batako standar dalam PUBI-1982 memberikan batasan standar bahwa untuk batako dengan nilai kuat tekan 2-3,5 MPa dapat dipakai pada konstruksi yang tidak memikul beban. Untuk kuat tekan $2 \mathrm{MPa}$ dapat dipasang pada tempat yang terlindung dari cuaca luar dan diberi lapisan pelindung.

\subsection{Serbuk Kaca}

Kaca adalah salah satu produk industri kimia yang merupakan gabungan dari berbagai oksida anorganik yang tidak mudah menguap, yang dihasilkan dari dekomposisi dan peleburan senyawa alkali dan alkali tanah, pasir serta berbagai penyusun lainnya, [9] [10]. Kandungan kimia di dalam bubuk kaca seperti Tabel 1 [2]:

Tabel 1. Kandungan Serbuk Kaca

\begin{tabular}{|l|l|}
\hline Unsur & Serbuk Kaca \\
\hline $\mathrm{SiO} 2$ & 61,72 \\
\hline $\mathrm{Al} 2 \mathrm{O} 3$ & 3,45 \\
\hline $\mathrm{Fe} 2 \mathrm{O} 3$ & 0,18 \\
\hline $\mathrm{CaO}$ & 2,59 \\
\hline
\end{tabular}

\section{A. Pengaruh Sifat Reaktif Silika pada Kaca}

Penggunaan agregat halus kaca yang dibuat dari jenis kaca leburan, mulai dikembangkan untuk membuat beton kinerja tinggi, [11]. Agregat halus kaca ini dibuat dalam bentuk bubuk dengan ukuran dan distribusi yang serupa agregat halus/pasir alam. Penggunaannya diharapkan dapat memanfaatkan limbahdari hasil samping industri untuk komponen industri konstruksi dan untuk mengatasi kekurangan pasir alam yang tersedia, [12][13]. Berdasarkan ASTM C289-87 dilakukan tes kimia dan tes kereaktifan agregat didapat bahwa bubuk kaca masih layak digunakan sebagai agregat walaupun memiliki sifat "merugikan" karena mengandung silika reaktif yang dapat bereaksi dengan alkali semen, sehingga mengakibatkan terjadinya ekspansi beton, [14].

Pada penelitian ini, bahan kaca yang dipakai untuk batako adalah serbuk kaca dari limbah kaca bening yang di dapat dari pengusaha etalase di Desa Plosokandang, Kedungwaru, Tulungagung.

\subsection{Teori Uji Kuat Tekan}

Kuat tekan (Compressive strength) adalah suatu bahan yang merupakan perbandingan besamya beban maksimum yangdapat ditahan dengan luas penampang bahan yang mengalami gaya tersebut, [15]. Kuat tekan batako mengidentifikasi mutu dari sebuah struktur. Semakin tinggi 
tingkat kekuatan struktur yang dikehendaki, semakintinggi pula mutu batako yang dihasilkan, [16][17].

Batako harus dirancang proporsi campurannya agar menghasilkan suatu kuat tekan rerata yang disyaratkan. Pada tahap pelaksanaan konstruksi, batako yang telah dirancang campurannya harus diproduksi sedemikian rupa sehingga memperkecil frekuensi terjadinya batako dengan kuat tekan yang lebih rendah dari seperti yang telahdisyaratkan. Untuk menghitung besamya kuat tekan dipergunakan persamaan [1].

$$
\mathrm{fc}=\frac{P}{A}
$$

Dengan :

$\mathrm{fc}=$ Kuat tekan $(\mathrm{MPa})$

$\mathrm{P}=$ Beban maksimum $(\mathrm{N})$

$\mathrm{A}=$ Luas penampang bahan $\left(\mathrm{mm}^{2}\right)$

\section{A. Penyerapan}

Besar kecilnya penyerapan air oleh batako sangat dipengaruhi oleh pori-pori atau rongga yang terdapat pada batako tersebut. Semakin banyak pori-pori yang terkandung dalam batako maka akan semakin besar pula penyerapan air sehingga ketahanannya akan berkurang, [18]. Rongga (pori-pori) yang terdapat pada batako terjadi karena kurang tepatnya kualitas dan komposisi material penyusunnya.Pengaruh rasio yang terlalu besar dapat menyebabkan rongga karena terdapat air yang tidak bereaksi dan kemudian menguap dan meninggalkan rongga (Sipayung.M. 1995).Persentase penyerapan air menggunakan persamaan.

Penyerapan Air $(\%)=\frac{m b-m k}{m k} \times 100 \%$

Dengan :

$\mathrm{mb}=$ Massa basah dari sampel $(\mathrm{gr})$

$\mathrm{mk}=$ Massa kering dari sampel $(\mathrm{gr})$

\subsection{Lokasi Penelitian}

Penelitian ini di lakukan di Laboratorium Dinas BINA MARGA, jalan Supriadi no 2 A, Kabupaten TRENGGALEK. Jenis penelitian ini adalah penelitian eksperimen di laboratorium berupa pengujian kuat tekan pada batako dengan penambahan serbuk kaca.Waktu penelitian direncanakan kurang lebih 1 bulan yakni mulai bulan Mei-Juli 2017.

\subsection{Peralatan Penelitian}

1. Saringan/Ayakan

2. Timbangan

3. Gelas ukur

4. Piknometer 
5. Cetakan benda uji

6. Oven

7. Sendok pemindah/Cepang

8. Bak air

9. Mesin uji kuat tekan

\subsection{Perencanaan Campuran}

Untuk menghitung jumlah kebutuhan tiap-tiap bahan, terlebih dahulu dilakukan pemeriksaan terhadap berat jenis (BJ) tiap-tiap bahan tersebut agar dapat dihitung komposisi bahan dari volume cetakan benda uji, [19] Berikut komposisi kebutuhan bahan untuk pembuatan benda uji dapat dilihat pada tabel 2 :

Tabel 2. Perhitungan Kebutuhan Bahan Perbenda Uji

\begin{tabular}{|c|c|c|c|c|c|}
\hline \multirow{3}{*}{$\begin{array}{l}\text { Penambahan } \\
\text { Serbuk }\end{array}$} & \multirow{3}{*}{ Benda } & \multicolumn{4}{|c|}{ Berat Bahan (gr) } \\
\hline & & & & Serbuk & \\
\hline & & Semen & Pasir & & Air \\
\hline \multirow[b]{2}{*}{$0 \%$} & Mortar & 268,4 & 2100 & 0 & 350 \\
\hline & Mortar & 268,4 & 2100 & 0 & 350 \\
\hline \multicolumn{2}{|c|}{ Total } & 536,8 & 4200 & 0 & 700 \\
\hline \multirow[b]{2}{*}{$10 \%$} & Mortar & 268,4 & 1890 & 210 & 350 \\
\hline & Mortar & 268,4 & 1890 & 210 & 350 \\
\hline \multicolumn{2}{|c|}{ Total } & 536,8 & 3780 & 420 & 700 \\
\hline \multirow[b]{2}{*}{$15 \%$} & Mortar & 268,4 & 1785 & 315 & 350 \\
\hline & Mortar & 268,4 & 1785 & 315 & 350 \\
\hline \multicolumn{2}{|c|}{ Total } & 536,8 & 3570 & 630 & 700 \\
\hline \multirow[b]{2}{*}{$20 \%$} & Mortar & 268,4 & 1680 & 420 & 350 \\
\hline & Mortar & 268,4 & 1680 & 420 & 350 \\
\hline \multicolumn{2}{|c|}{ Total } & 536,8 & 3360 & 840 & 700 \\
\hline \multirow{2}{*}{$25 \%$} & Mortar & 268,4 & 1575 & 525 & 350 \\
\hline & Mortar & 268,4 & 1575 & 525 & 350 \\
\hline \multicolumn{2}{|l|}{ Total } & 536,8 & 3150 & 1050 & 700 \\
\hline
\end{tabular}

\subsection{Desain Benda Uji}

Perancangan campuran bahan penyusun batako dengan perbandingan $1: 6$ semen dan pasir. Pembuatan benda uji ukuran dan tampak luar dan pengujian daya serap menggunakan benda uji mortar ukuran $5 \times 5 \times 5 \mathrm{~cm}$. Untuk pengujian kuat tekan menggunakan benda uji mortar ukuran $5 \times 5 \times 5 \mathrm{~cm}$. Variasi penambahan serbuk kaca dengan mengurangi jumlah pasir mulai dari $0 \%, 10 \%, 15 \%, 20 \%$, dan $25 \%$ dari berat pasir dengan benda uji masing-masing 
2 buah untuk setiap komposisi benda uji. Jumlah benda uji yang akan dibuat dapat dilihat pada tabel 3. dibawah:

Tabel 3. Jumlah benda uji

\begin{tabular}{|c|c|c|}
\hline \multirow{2}{*}{ Mortar } & \multirow{2}{*}{$\begin{array}{c}\text { Umur } \\
\text { Pengujian } \\
\text { (Hari) }\end{array}$} & $\begin{array}{l}\text { Jumlah } \\
\text { Sampel }\end{array}$ \\
\hline & & Mortar \\
\hline \multirow{3}{*}{ Mortar 0\% } & 7 & 2 \\
\hline & 14 & 2 \\
\hline & 28 & 2 \\
\hline \multirow{3}{*}{ Mortar $10 \%$} & 7 & 2 \\
\hline & 14 & 2 \\
\hline & 28 & 2 \\
\hline \multirow{3}{*}{ Mortar $15 \%$} & 7 & 2 \\
\hline & 14 & 2 \\
\hline & 28 & 2 \\
\hline \multirow[b]{3}{*}{ Mortar $20 \%$} & 7 & 2 \\
\hline & 14 & 2 \\
\hline & 28 & 2 \\
\hline \multirow[b]{3}{*}{ Mortar 25\% } & 7 & 2 \\
\hline & 14 & 2 \\
\hline & 28 & 2 \\
\hline Jumlah & & 30 \\
\hline
\end{tabular}

\subsection{Metode Pengecoran}

Langkah-langkah pembuatan benda uji adalah sebagai berikut:

1. Alat-alat yang akan digunakan dibersihkan terlebih dahulu, kemudian menimbang bahan-bahan yang akan digunakan sesuai dengan komposisi yang telah di tentukan

2. Menyiapkan alat dan tempat untuk pengadukan. Kemudian tuangkan pasir dan semen yang sudah di timbang sesuai dengan komposisinya. Aduk hingga kedua bahan tersebut tercampur merata.

3. Setelah kedua bahan tersebut tercampur rata, tuangkan air sedikit demi sedikit (untuk batako normal), dan serbuk kaca (untuk batako serbuk kaca) secarabergantian sesuai dengan variasi yang telah ditentukan.

4. Setelah tercampur rata, selanjutnya adukandituangkan ke dalam cetakan mortar, dan di padatkan agarcampuran mortar menjadi padat. 
5. Diamkan selama 24 jam.

6. Setelah 24 jam buka cetakan dan mulai melakukan perawatan benda uji.

\subsection{Perawatan Benda Uji}

Perawatan benda uji dilakukan dengan cara direndam dalam bak perendaman. Benda uji diangkat dari bak \pm 8 jam sebelum sampel di uji, setelah itu di panaskan dan sering dilakukan pengontrolan. Hal ini dimaksudkan agar pada waktu di uji, sampel dalam keadaan kering SSD.

Pengujian dilakukan pada saat sampel berumur 7, 14, 28 hari, [20]. Hal ini berarti benda uji diangkat dari bak rendam saat berumur 7 hari sebanyak 10 benda uji, umur 14 hari sebanyak 10 benda uji, dan umur 28 hari sebanyak 10 benda uji.

\subsection{0.. Pengujian Benda Uji}

Adapun pengujian untuk masing-masing benda uji adalah sebagai berikut :

1. Pengujian daya serap dengan benda uji mortar ukuran $5 \times 5 \times 5 \mathrm{~cm}$ menggunakan oven dan timbangan. Pengujian dilakukan pada umur 28 hari untuk semua variasi.

2. Pengujian kuat tekan dengan benda uji mortar ukuran 5 × 5 × $5 \mathrm{~cm}$ menggunakan mesin uji kuat tekan beton (compression machine). Pengujian dilakukan pada umur 7, 14, dan 28 hari untuk semua variasi.

\section{HASIL DAN PEMBAHASAN}

\subsection{Analisa Saringan Agregat Halus}

Hasil pengujian karakteristik agregat halus.Hasil pengujiandapat dilihat pada table 4 .

Tabel 4. Rekapitulasi Hasil Pengujian Agregat Halus

\begin{tabular}{|c|c|c|c|c|}
\hline $\begin{array}{c}\text { SIEVE } \\
\text { NO. }\end{array}$ & $\begin{array}{c}\text { DIAMETER } \\
(\mathrm{mm})\end{array}$ & $\begin{array}{c}\text { SAMPEL } \\
(\mathrm{A}) \\
\text { \% PASS. }\end{array}$ & $\begin{array}{c}\text { SAMPEL } \\
\text { \% PASS. }\end{array}$ & AVERAGE \\
\hline$\# 11 / 2$ & 37.5 & 100.00 & 100.00 & 100.00 \\
\hline$\# 3 / 4$ & 19 & 100.00 & 100.00 & 100.00 \\
\hline$\# 3 / 8$ & 9.5 & 96.13 & 95.30 & 95.72 \\
\hline$\# 4$ & 4.75 & 92.62 & 91.67 & 92.14 \\
\hline$\# 8$ & 2.36 & 85.58 & 85.62 & 85.60 \\
\hline$\# 16$ & 1.18 & 72.16 & 71.95 & 72.06 \\
\hline$\# 30$ & 0.6 & 38.73 & 38.35 & 38.54 \\
\hline$\# 50$ & 0.3 & 13.20 & 14.50 & 13.85 \\
\hline$\# 100$ & 0.15 & 1.03 & 1.15 & 1.09 \\
\hline$\# 200$ & 0.075 & 0.03 & 1.07 & 0.55 \\
\hline
\end{tabular}

Sumber : Pengolahan data 


\subsection{Hasil Pengujian Daya Serap Mortar}

Berikut merupakan rekapitulasi hasil pemeriksaan daya serap mortar dari kelima macam komposisi yang telah di uji.Seperti pada tabel 5.

Tabel 5. Rekapitulasi hasil daya serap mortar

\begin{tabular}{|c|c|c|}
\hline $\begin{array}{c}\text { Variasi } \\
\text { Komposisi (\%) }\end{array}$ & $\begin{array}{c}\text { Umur Pengujian } \\
\text { (Hari) }\end{array}$ & Resapan \\
& 28 & 8.015 \\
\hline 0 & 28 & 10.532 \\
\hline 10 & 28 & 10.672 \\
\hline 15 & 28 & 10.701 \\
\hline 20 & 28 & 11.187 \\
\hline 25 &
\end{tabular}

Sumber : Pengolahan data

\subsection{Hasil Pengujian Kuat Tekan Mortar}

Mesin yang di gunakan pada penelitian ini adalah mesin kuat tekan hidrolik.Adapun hasil perhitungan kuat tekan mortar dapat dilihat pada Tabel 6.

Tabel 6. Hasil Pengujian Kuat Tekan pada umur 28 Hari

\begin{tabular}{|c|c|c|c|c|}
\hline NO & KOMPOSISI & $\begin{array}{c}\text { UMUR } \\
\text { BENDA } \\
\text { UJI }\end{array}$ & $\begin{array}{c}\text { TEGANGAN } \\
\text { TEKAN HANCUR } \\
\text { Kg/Cm }\end{array}$ & $\begin{array}{c}\text { KONVRENSI } \\
\text { UMUR MORTAR } \\
\text { Kg/Cm }\end{array}$ \\
\hline 1 & $0 \%$ & 28 & 36.40 & 36.40 \\
\hline 2 & $0 \%$ & 28 & 36.80 & 36.80 \\
\hline 3 & $10 \%$ & 28 & 37.60 & 37.60 \\
\hline 4 & $10 \%$ & 28 & 37.40 & 37.40 \\
\hline 5 & $15 \%$ & 28 & 39.20 & 39.20 \\
\hline 6 & $15 \%$ & 28 & 37.60 & 37.60 \\
\hline 7 & $20 \%$ & 28 & 40.80 & 40.80 \\
\hline 8 & $20 \%$ & 28 & 49.60 & 49.60 \\
\hline 9 & $25 \%$ & 28 & 61.60 & 61.60 \\
\hline 10 & $25 \%$ & 28 & 54.40 & 54.40 \\
\hline
\end{tabular}

Sumber : Pengolahan data

\section{KESIMPULAN}

Berdasarkan hasil penelitian dan pembahasan, maka dapat ditarik kesimpulan sebagai berikut :

1. Penyerapan mortar dipengaruhi oleh besarnya volume serbuk kaca dalam campuran mortar. Dimana semakin besar volume serbuk kaca maka semakin tinggi penyerapan 
yang dihasilkan. Mortar dengan campuran serbuk kaca 0\%, 10\%, 15\%, 20\%, dan 25\% mempunyai nilai penyerapan air rata-rata sebesar 8,01\%, 10,53\%, 10,67\%, 10,70\% dan $11,19 \%$.

2. Penambahan $25 \%$ serbuk kaca dari volume mortar mencapai titik tertinggi dalam percobaan ini, yaitu dengan nilai rata-rata kuat tekan $58,00 \mathrm{~kg} / \mathrm{cm}^{2}$. Namun peneliti belum menemukan titik turun kuat tekan dari hasil pengujian ini.

3. Kuat tekan mortar dipengaruhi oleh besarnya volume serbuk kaca dalam campuran mortar. Dimana semakin besar volume serbuk kaca maka semakin tinggi kuat tekan yang dihasilkan. Nilai kuat tekan dengan volume serbuk kaca 0\%, 10\%, 15\%, 20\% dan 25\% rata-rata pada umur 7 hari berturut-turut adalah $23,20 \mathrm{~kg} / \mathrm{cm}^{2}, 27,40 \mathrm{~kg} / \mathrm{cm}^{2}, 30,40$ $\mathrm{kg} / \mathrm{cm}^{2}, 33,80 \mathrm{~kg} / \mathrm{cm}^{2}, 38,80 \mathrm{~kg} / \mathrm{cm}^{2}$. Nilai kuat tekan dengan volume serbuk kaca $0 \%$, $10 \%, 15 \%, 20 \%$, dan $25 \%$ rata-rata pada umur 14 hari berturut- turut adalah 31,00 $\mathrm{kg} / \mathrm{cm}^{2}, 33,00 \mathrm{~kg} / \mathrm{cm}^{2}, 36,80 \mathrm{~kg} / \mathrm{cm}^{2}, 40,80 \mathrm{~kg} / \mathrm{cm}^{2}, 51,00 \mathrm{~kg} / \mathrm{cm}^{2}$. Nilai kuat tekan dengan volume serbuk kaca $0 \%, 10 \%, 15 \%, 20 \%$ dan $25 \%$ rata-rata pada umur 28 hari berturut-turut adalah $36,60 \mathrm{~kg} / \mathrm{cm}^{2}, 37,50 \mathrm{~kg} / \mathrm{cm}^{2}, 38,40 \mathrm{~kg} / \mathrm{cm}^{2}, 45,20 \mathrm{~kg} / \mathrm{cm}^{2}$ dan $58,00 \mathrm{~kg} / \mathrm{cm}^{2}$.

4. Dari semua hasil penelitian diatas, dapat dinyatakan bahwa serbuk kaca dapat digunakan sebagai bahan tambah dalam pembuatan batako.

\section{SARAN}

Berdasaarkan kesimpulan diatas maka diajukan beberapa saran berikut ini:

1. Diperlukan kelanjutan dari penelitian ini, untuk mengetahui pada komposisi berapa hasil uji kuat tekan akan menurun.

2. Memperbanyak jumlah sampel. Pada penelitian ini jumlah sampel pengujian relatif sedikit yang memungkinkan adanya keterbatasan data.

3. Diperlukan peleburan lebih lanjut sampai kaca benar-benar menjadi serbuk dengan diameter sekecil mungkin untuk mencari prosentase tingkat ketajaman seminimum mungkin, agar tidak membahayakan pekerja.

4. Perlu diperhatikan dengan teliti mulai dari proses perancangan benda uji mortar, proses persiapan bahan dan alat, proses pengerjaan benda uji mortar sampai proses perawatan benda uji mortar sehingga didapat bendauji dengan kualitas yang diinginkan.

5. Penelitian lebih lanjut, harap di perhatikan jumlah atau kekuatan pukulan pada waktu memasukkan adonan ke dalam cetakan, atau di lakukan dengan alat hidrolis.

\section{UCAPAN TERIMAKASIH}

Dalam penyusunan artikel ini, penulis ucapkan terimakasih kepada dosen pembimbing dan Universitas Kadiri. Penulis berharap agar artikel ini dapat bermanfaat bagi pembaca. 


\section{DAFTAR PUSTAKA}

[1] C. Habsya, A. Rahmawati, and S. Sumarni, "Lockbrick Modular Beton Untuk Alternatif Bahan Dinding," sinektika, vol. 14, no. 2, pp. 234-242, 2004.

[2] L. Wibowo, "Pengaruh penambahan serbuk kaca dan WATER REDUCING HIGH RANGE ADMIXTURES TERHADAP KUAT DESAK DAN MODULUS ELASTISITAS PADA BETON," 2013.

[3] B. S. Nasional, “Sni 03-0349-1989," Bata Bet. untuk pasangan dinding, 1989.

[4] H. Mallisa, "Studi Kelayakan Kualitas Batako Hasil Produksi Industri Kecil di Kota Palu," Media Litbang Sulteng, vol. 4, no. 2, pp. 75-82, 2011.

[5] Badan Standardisasi Nasional, "SNI 03-0691-1996 Bata Beton."

[6] G. Gunawan, P. Nawangsari, and D. Masnur, "STUDI PEMANFAATAN LIMBAH KACA DAN PISTON BEKAS SEBAGAI MATERIAL ALTERNATIF KANVAS REM SEPEDA MOTOR DENGAN MENGGUNAKAN METODE METALURGI SERBUK," Jom FTEKNIK, vol. 3, no. 2, pp. 1-6, 2016.

[7] Ristinah, A. Zacoeb, A. Soehardjono, and D. Setyowulan, "Pengaruh Penggunaan Bottom Ash Sebagai Pengganti Semen Pada Campuran Batako Terhadap Kuat Tekan Batako," Rekayasa Sipil, vol. 6, no. 3, pp. 264-271, 2012.

[8] Rahmat, I. Hendriyani, and R. Sa'diyah, "ANALISIS BATAKO DENGAN CAMPURAN SERBUK KACA SEBAGAI PENGGANTI PASIR.”

[9] B. Herbudiman and C. Januar, "PEMANFAATAN SERBUK KACA SEBAGAI POWDER PADA SELF-COMPACTING CONCRETE,” 2011.

[10] I. Handayasari, "STABILISASI TANAH PADA LAHAN BEKAS TEMPAT PEMBUANGAN AKHIR (TPA) SAMPAH DENGAN PEMANFAATAN SERBUK LIMBAH BOTOL KACA SEBAGAI BAHAN CAMPURAN.”

[11] Kosim and A. Hasan, "Pemanfaatan Serbuk Kaca Sebagai Bahan Tambah Agregat Halus Untuk Meningkatkan Kuat Tekan Beton,” J. Tek. Sipil, vol. 10, no. 2, pp. 170-178, 2014.

[12] H. Purnomo and E. S. Hisyam, "PEMANFAATAN SERBUK KACA SEBAGAI SUBSTITUSI PARSIAL SEMEN PADA CAMPURAN BETON DITINJAU DARI KEKUATAN TEKAN DAN KEKUATAN TARIK BELAH BETON,” J. Fropil, vol. 2, no. 1, pp. 45-55, 2014.

[13] Nursyamsi, I. Indrawan, and I. P. Hastuty, "PEMANFAATAN SERBUK KACA 
SEBAGAI BAHAN TAMBAH DALAM PEMBUATAN BATAKO,” 2016.

[14] A. A. F. Putra, "Karakteristik Beton Ringan dengan Bahan Pengisi Styrofoam," 2015.

[15] SNI 4431:2011, "Cara uji kuat lentur beton normal dengan dua titik pembebanan," Standar Nas. Indones., p. 16, 2011.

[16] M. A. Punusingon, B. D. Handono, and R. Pandaleke, "UJI EKSPERIMENTAL KUAT TEKAN BETON DAUR ULANG DENGAN BAHAN TAMBAH ABU TERBANG (FLY ASH) DAN SERBUK KACA SEBAGAI SUBSTITUSI PARSIAL SEMEN," Sipil Statik.

[17] N. Rasif, I. S. Dewi, N. Aviani, and W. Utama, “ANALISIS KUAT TEKAN DAN DENSITAS BETON NON-PASIR DENGAN CAMPURAN VARIAN ABU TERBANG MENGGUNAKAN MATLAB," PROKONS.

[18] D. P. Kusumastuti, I. Sepriyanna, and Hastanto, "Perubahan Angka Pori Tanah Lunak Terstabilisasi dengan serbuk kaca dan serat karung plastik,” Semnastek.

[19] Badan Standarisasi Nasional, "SNI 7656-2012 Tata Cara Pemilihan Campuran Beton Normal, Beton Berat, dan beton Massa," 2012.

[20] M. Ramadhan, Budiono, and T. P. Artiningsih, "PENGARUH PROSES CURING DENGAN CARA PERENDAMAN DALAM AIR MENDIDIH TERHADAP BETON REAKTIF SEMEN," pp. 1-11. 